\title{
DERECHOS Y FRONTERAS \\ La condición de extranjero como rasgo inmutable de las personas: una revisión crítica de las prácticas actuales de exclusión de extranjeros ${ }^{1}$
}

Victoria Roca

Universidad de Alicante

\section{Introducción}

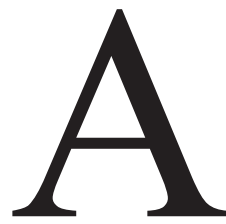

1 igual que ocurre con otras muchas dicotomías que se han sucedido a lo largo de la historia, la dicotomía ciudadano/ extranjero puede ser cuestionada a la luz de la exigencia moral de la igualdad de trato. Someter a consideración esta distinción implicará por un lado revisar algunas ideas acerca de nuestras prácticas en relación con el fenómeno inmigratorio que, si bien se hallan muy asentadas no por ello dejan de ser menos perturbadoras, y, por otro, subrayar las complejidades normativas -así como fácticas- que surgen cuando tratamos de implementar el mencionado principio de igualdad.

1. El objetivo del presente trabajo es introducir aunque sea de forma muy tentativa algunas reflexiones acerca de las políticas en relación con la inmigración tomando para ello como referencia las perspectivas abiertas en uno [...] de los debates de mayor interés que actualmente tienen lugar en la filosofía política: el debate acerca de la legitimidad de los Estados una vez puesta en duda su eficacia -en un mundo económicamente globalizado- como agentes responsables de la protección e implementación de los derechos humanos ${ }^{2}$. Sin duda, el llamado Estado-Nación ha jugado históricamente un rol muy importante tanto en el proceso de democratización de muchas sociedades occidentales $^{3}$ como en el diseño y puesta en práctica del modelo de Estado social (Welfare State). Sin embargo, pudiera ser que el desarrollo de nuestras sociedades haya tomado un curso tal que el modelo de Estado-Nación que

${ }^{1}$ Un borrador de este trabajo fue presentado bajo el título de Rights and Borders (Alienage as an immutable characteristic: current practices on alien exclusion under scrutiny) en la III sesión de las PhD Euroconferences on Legal Theory celebrada en Génova del 14 al 16 de Noviembre de 2003.

${ }^{2}$ En este sentido puede verse FERRAJOLI 1999: 55-58, 116-119.

${ }^{3}$ Véase Habermas 1990: 619-643. 
implica la división del territorio a partir de fronteras políticas carezca de o, al menos, haya visto minada de alguna forma sustantiva su legitimidad moral.

En efecto, en relación con las prácticas que discutiré en este trabajo, podría suceder que en nuestro tiempo, más que nunca, se haya puesto de manifiesto el carácter moralmente sospechoso de la distinción extranjero/ nacional trazada por los sistemas jurídicos nacionales ${ }^{4}$ (incluyendo aquí el caso de organizaciones políticas más complejas como la Unión Europea). O, para expresarlo en términos que supongan un desafío menor a este modelo de organización social, acaso exista un imperativo moral que nos conmina a reconsiderar al menos algunos aspectos de la división política del mundo así como de otras estructuras sociales que pudieran estar dando soporte a distribuciones injustas de recursos y oportunidades básicas. En pocas palabras, me parece que de alguna forma estamos obligados a reconsiderar las causas de la distribución actual de riqueza y de poder que vienen a colocar a una gran mayoría de seres humanos muy lejos de que se respeten en relación con ellos las condiciones de vida protegidas, entre otros, por el artículo 25 de la Declaración Universal de los Derechos Humanos: "Toda persona tiene derecho a un nivel de vida adecuado que le asegure, así como a su familia, la salud y el bienestar, y en especial la alimentación, el vestido, la vivienda, la asistencia médica y los servicios sociales necesarios; tiene asimismo derecho a los seguros en caso de desempleo, enfermedad, invalidez, viudez, vejez u otros casos de pérdida de sus medios de subsistencia por circunstancias independientes de su voluntad".

2. Debemos, pues, enfrentarnos a la cuestión de cómo satisfacer la exigencia moral de igualdad de oportunidades en términos como los conceptualizados, por ejemplo, en la obra de Amartya Sen ${ }^{5}$. Y, quizá en una clave más abstracta pero también más esclarecedora, ello nos compele asimismo a enfrentar las complejidades que surgen del principio de dignidad, valor recogido como fundamental -al margen de todas sus oscuridades teóricas- en muchas Constituciones de las democracias occidentales y en proyectos constitucionales como el de la Unión Europea ${ }^{6}$.

3. En su trabajo Derecho de gentes ${ }^{7}$, Rawls enumera las causas de los flujos migratorios sin entrar, sin embargo, en un análisis profundo de las políticas de control de los mismos limitándose a sugerir meramente que tales causas desaparecerían en una "utopía realista de sociedad de pueblos libe-

\footnotetext{
${ }^{4}$ Véase Hierro 1995: 137-145 y Atienza 2001: 203-209.

${ }^{5}$ Véase las nociones de capacidades y autonomía [agency] en su trabajo Desarrollo y libertad (2000).

${ }^{6}$ Véase el Proyecto de Constitución Europea, Salónica, Junio, 2003, parte II, Derechos fundamentales de la Unión, Preámbulo y Título I, artículo II.1.

${ }^{7}$ RAWLS 1999: 8-9.
} 
rales o decentes" (realistic utopia of society of liberal and decent Peoples). También se echa de menos en su análisis, en mi opinión, la consideración de uno de los factores principales de los movimientos migratorios en nuestros días -al que sólo se refiere de forma indirecta y a otros propósitos de su argumentación-, a saber, las tiranías de poder económico -que son el resultado de desarrollos históricos de ciertas estructuras de mercado- y las sociedades sometidas a ellas ${ }^{8}$.

En el presente trabajo, y bajo la luz arrojada por el principio de igualdad de oportunidades o, en última instancia, por el principio de dignidad de la persona entendido éste en un sentido igualitarista, me centraré en el problema de los refugiados por razones económicas ${ }^{9}$. Entiendo que el caso de quienes emigran a terceros países en busca de mejores condiciones materiales de vida plantea retos más importantes a nuestras políticas que el de los denominados refugiados políticos. Aunque las condiciones para considerar a alguien como un refugiado político se han endurecido actualmente (los líderes políticos europeos establecieron hace unos meses una lista de países que debían ser considerados "seguros" a los efectos de concesión de tal status $^{10}$ ), me parece, sin embargo, que en el marco de tales políticas aceptar que alguien es verdaderamente un refugiado político tiene como consecuencia aceptar a tal persona en una de las comunidades políticas liberales (al menos en la medida en que el número de refugiados políticos continúe no siendo excesivamente elevado). Pero no es éste el proceder cuando lo que está en juego son intereses relativos a la calidad de vida de quien emigra a un tercer país: tal es el caso de los que -recogiendo una terminología extendida- antes he denominado refugiados por razones económicas. De ahí que someter a examen estos supuestos pueda presentarse, creo, como el mejor test posible a partir de cuyos resultados, perturbadores en muchos puntos, se requeriría acaso inyectar cierto renovado impulso moral a nuestras políticas de fronteras.

4. Cuando sometemos a consideración los flujos migratorios hay otra distinción que resulta también relevante: la distinción entre políticas de entrada y políticas de integración. Se trata, sin embargo, de una distinción poco nítida. Las políticas de integración suscitan cuestiones tales como el debate acerca de la naturaleza de la ciudadanía, las implicaciones del multiculturalismo, el reclamo de igualdad de derechos para todos aquellos que viven en una misma comunidad política (igualdad en el acceso a las

\footnotetext{
${ }^{8}$ RAWLS 1999: 106.

${ }^{9}$ Véase Singer 1995: 308-328

${ }^{10}$ Pueden verse en este sentido las críticas de Habermas a las restricciones legales en Alemania a comienzos de los 90 en HaBERMAs 1993: 149-153.
} 
prestaciones sociales, al trabajo e igual disfrute de los derechos y deberes de la vida política). Las políticas de entrada están relacionadas con problemas tales como, por una parte, qué requisitos satisfacer para ser aceptados ya sea simplemente en el territorio o, finalmente, en la comunidad (requisitos que, por cierto, no dependen todos ellos en su posibilidad de cumplimiento de quienes desean entrar a un determinado país), y, por otra parte, con las condiciones a ser también satisfechas para no ser expulsado (como veremos, quienes pasan a naturalizarse como ciudadanos de un país o disfrutan de un permiso temporal o permanente de residencia deben cumplir el requisito de "buen comportamiento" bajo riesgo de deportación como segunda pena unida a la pena ordinaria de prisión en determinados delitos). El debate acerca de las condiciones de entrada es el núcleo de la controversia acerca del tema de la apertura o clausura (o restricción en el paso) de las fronteras y en el marco de la actualmente desequilibrada "sociedad de Estados-Nación", es éste también el debate acerca de uno de los posibles pasos hacia la igualdad de oportunidades. Por lo demás, hay muchos problemas que vienen a conectar las políticas de entrada y las de integración (la reunificación familiar, como podremos ver, es uno de ellos).

5. La posición de debilidad y vulnerabilidad es muy probablemente el rasgo común que comparten la mayor parte de quienes aspiran a traspasar las fronteras de un determinado país de acogida. Nuestras políticas inmigratorias, al tiempo que se presentan como protectoras de los individuos que se encuentran en tal posición (sistemas policiales orientados a evitar el tráfico de seres humanos), terminan siendo sin embargo muchas veces una mera gestión administrativa de dicha vulnerabilidad. Las cuotas temporales de acceso -que aceptan en los países de entrada sólo a aquellos trabajadores que resultan de utilidad para el desempeño de cierto tipo de trabajos y garantizándoles sólo permisos en la medida en que su permanencia venga dictada por exigencias de la economía nacional: véase en este sentido el artículo 42 de la Ley española de extranjería $8 / 2000^{11}$ - pueden ser un ejemplo ilustrativo de aquello a lo que me refiero cuando hablo de la "gestión administrativa de la vulnerabilidad".

6. El núcleo mínimo del derecho a emigrar puede ser definido como un derecho humano que el individuo tiene frente al Estado en el cual reside: "Toda persona tiene el derecho a dejar cualquier país", establece el artículo 13 de la Carta de Derechos Humanos de las Naciones Unidas. Incluso este mínimo contenido se nos presentaría como suficiente para condenar las pretensiones mantenidas actualmente por algunos países occidentales de-

\footnotetext{
${ }^{11}$ En este punto la Ley orgánica 8/2000 no ha sido alterado por la Ley orgánica 14/2003.
} 
mandando un compromiso por parte de los países del norte de África en el sentido de evitar que sus nacionales emigren a los primeros.

Más allá de ese núcleo mínimo del derecho humano a emigrar, creo sin embargo que podría plantearse si el tomar en serio tal derecho particular implicaría compromisos superiores en relación con los individuos que desean ser aceptados en determinadas comunidades políticas. El conflicto de valores que se presenta en una hipotética conversación en la frontera será objeto de reflexión en un apartado posterior de este trabajo.

7. A fin de llevar a cabo un análisis crítico de las prácticas actuales en materia de inmigración he estudiado materiales de diferentes tipos. Presentaré algunos materiales normativos que son actualmente Derecho positivo. Tal como sostiene Ferrajoli ${ }^{12}$, disponemos de un conjunto de normas que constituyen Derecho en vigor aun cuando sean constantemente violadas por la legislación estatal sobre extranjería e inmigración. Entre tales documentos normativos mencionaré: la Carta de Derechos Humanos de las Naciones Unidas, la Convención Europea para la protección de los Derechos Humanos y Libertades Fundamentales, la Carta de Derechos Sociales, las diferentes convenciones sobre Derechos del niño de las Naciones Unidas, los catálogos de derechos fundamentales recogidos en la mayoría de Constituciones de los países occidentales y el ya mencionado proyecto de Constitución de la Unión Europea. La pretensión de universalidad que se invoca para los valores y principios protegidos por dichos textos viene considerándose la fuente de legitimidad moral de las sociedades occidentales, incluyéndose aquí los derechos civiles y políticos, los derechos al desarrollo de la vida privada, los derechos económicos y sociales, el principio de igualdad en sus diversas manifestaciones, etcétera. El principio de la dignidad humana es la pieza clave de las mencionadas cartas. De modo específico, el artículo 2 del proyecto de Constitución de la Unión Europea sienta los denominados "valores de la Unión": La Unión se fundamenta en los valores de respeto a la dignidad humana, libertad, democracia, igualdad, Estado de Derecho y protección de los derechos humanos. Me referiré igualmente al principio de dignidad más adelante.

Entre los materiales jurídicos he analizado también un conjunto de sentencias del Tribunal Europeo de Derechos Humanos. Las considero especialmente interesantes para los propósitos del presente trabajo por cuanto que ofrecen, a mi juicio, el mejor test para identificar la ponderación de intereses que actualmente se practica en relación con las políticas estatales en materia de inmigración. Si bien este Tribunal podría haber supuesto un importante referente en el desarrollo de las políticas estatales en la materia

\footnotetext{
${ }^{12}$ Ferrajoli 2001: 335-336.
} 
y haber jugado así un papel decisivo en la implementación universal de la igualdad y los derechos humanos, de hecho ha operado de un modo muchas veces excesivamente complaciente con las políticas estatales. En efecto, en numerosas ocasiones ha venido a debilitar mediante ambiguas rationes decidendi cualquier expectativa optimista frente a decisiones futuras en relación con la realización efectiva de las exigencias igualitaristas. Las circunstancias prácticas nos hacen adivinar, no obstante, que ese timorato papel es el precio que ha de pagar el Tribunal Europeo de Derechos Humanos para garantizar la eficacia de sus sentencias en los distintos Estados miembros.

Dar cuenta de la normas vigentes exige también presentar las líneas principales del proyecto - tal y como fue trazado en los diversos encuentros del Consejo (Tampere, Laecken, Tessalonika y Bruselas)- orientado a conseguir una política de convergencia en materia de inmigración en la Unión Europea.

8. Mi aproximación intenta ser un modesto ejercicio de equilibrio reflexivo. La lectura de las historias individuales que fueron llevadas como casos ante el Tribunal Europeo de Derechos Humanos y dieron lugar a sus resoluciones, así como de las implicaciones de las mismas en relación con posibles casos futuros pueden instalarnos en algún género de incomodidad que no aparecería de forma tan vívida si comenzáramos perfilando normas generales y prácticas a seguir. Me propongo entonces entresacar y dibujar los balances de valores llevados a cabo en tales decisiones así como los encarnados en la política europea de convergencia en materia de inmigración. Tras ello, introduciré los análisis teóricos de Walzer, Singer, Habermas y Ackerman. La aportación de Ackerman me ayudará a presentar el análisis que considero relevante para mis propósitos en este trabajo y que es en concreto el análisis centrado en el núcleo del principio de dignidad entendido en clave igualitarista.

9. Concluiré esta introducción con un último caveat. Mi intención en las páginas que siguen es llevar a cabo una reflexión sobre las cuestiones apuntadas evitando expresamente dos tipos de aproximaciones a las que -usando términos hegelianos- podríamos considerar inspiradas en la apelación a la "conciencia desventurada" y al "espíritu objetivo".

Un análisis crítico de nuestros deberes morales (negativos y positivos) como ciudadanos de una de las sociedades occidentales opulentas puede ciertamente mostrarnos un cuadro que nos haría percatarnos de cómo nuestra moralidad convencional puede muy bien ser denominada-como ya lo ha sido- una "moral yuppie" a partir del hecho de que casi cualquier acto de dar es considerado como un "sacrificio heroico" una vez que nos sentimos mínimamente incomodados en nuestro actual -opulento- "estilo de vida"13.

\footnotetext{
${ }^{13}$ Puede verse en este sentido BAYÓN 1986: 35-54.
} 
Ahora bien, esto -que desde luego pudiera ser importante para agitar tal vez algunas pocas conciencias- podría parecer meramente un "discurso de denuncia" con desafortunadamente escasas consecuencias en términos de cualquier intento serio y realista por cambiar nuestras instituciones. Por otra parte, sin embargo, contamos también con la desesperanza de la consabida letanía del "lo que es debe ser". Quizás el camino para trazar un análisis sensato y realista sin caer en ninguno de ambos extremos podría consistir en plantear una pregunta marco que permita orientar nuestra reflexión. Sugiero la siguiente: a la luz de las exigencias igualitaristas y de la universalización de los derechos humanos, ¿qué tipo de políticas públicas podrían ser propuestas, realistamente hablando, para la realización de esos ideales a la vista de las características del concepto actual de ciudadanía de nuestros Estados? La moralidad nos compromete a hablar en términos del mejor de los mundos posibles. La política nos recuerda que construir ese mejor mundo posible es una tarea colectiva en la que debería alcanzarse un consenso de todas las fuerzas políticas, al menos si deseamos evitar el riesgo de ver cómo nuestro proyecto está lejos de ser realizable y cómo nuestras sociedades se ven amenazadas por movimientos xenófobos que podrían ganar creciente influencia en los parlamentos democráticos.

\section{La jurisprudencia del Tribunal Europeo de Derechos Humanos sobre asuntos relacionados con la inmigración}

10. He elegido cinco sentencias dictadas por el Tribunal Europeo de Derechos Humanos (TEDH) en los siguientes casos: Ahmut vs. Holanda (1996), Sen vs. Holanda (2001), Moustaquim vs. Bélgica (1991), Bensaid vs. Reino Unido (2001) y Cisse vs. Francia (2002).

Los dos primeros casos tienen que ver con las implicaciones de las actuales políticas de inmigración en la vida familiar. Las dos siguientes sentencias conciernen a órdenes de deportación. En el último caso lo que está en cuestión es el derecho de reunión de las "personas indocumentadas".

Dados los propósitos de mi trabajo no pretendo entrar en detalle ni en las circunstancias de estos distintos casos ni en los argumentos individuales de cada sentencia. Me limitaré a presentar un breve apunte de los supuestos fácticos discutidos, un cuadro de los intereses en juego y un esquema de la ponderación de dichos intereses tal como fue llevado a cabo por el TEDH.

Los casos Ahmut (1996) y Sen (2001) se refieren ambos a inmigrantes por razones económicas establecidos en un país europeo que decidieron traer consigo a sus hijos pequeños a los que habían inicialmente dejado en su país de origen. Ahmut poseía nacionalidad marroquí y ciudadanía europea por naturalización. Pese a los años que había pasado en Holanda, y pese a su condición adquirida de ciudadano de este país, el Tribunal consideró 
que la denegación de un permiso a su hijo de nueve años de edad, que le hubiera permitido vivir con él en Holanda, no constituía una interferencia en su vida familiar (prohibida por el artículo 8) dado que el Tribunal creyó aplicables aquí los principios de Gül vs. Suiza (1996). Tales principios eran los siguientes:

a) Las obligaciones de los Estados en relación con la admisión de familiares de inmigrantes ya establecidos en su territorio varían atendiendo a las circunstancias especificas de las personas implicadas y al interés general del Estado en cuestión.

b) El Derecho Internacional reconoce a los Estados, si bien dentro de las obligaciones que surgen de los tratados, el derecho a controlar la entrada de no nacionales en su territorio.

c) En lo que se refiere a la inmigración, el artículo 8 no puede interpretarse en el sentido de entender que los Estados tienen la obligación de respetar la elección de país que para su residencia matrimonial haga el inmigrante y de autorizar la reunificación familiar en su territorio.

Por lo que concierne a este caso en particular, el Tribunal considera que a S. Ahmut no se le impidió ni mantener el grado de vida familiar por el cual él mismo había optado cuando se trasladó inicialmente a Holanda, ni tampoco se le impuso obstáculo alguno para volver a Marruecos. Aun si Ahmut hubiera preferido mantener e incluso intensificar sus lazos familiares con su hijo en Holanda, el artículo 8 -según la interpretación del Tribunal- no garantiza el derecho a elegir el lugar más adecuado para desarrollar la vida familiar. Por otra parte, el Tribunal no considera tener la obligación de abordar la cuestión acerca de si los familiares del hijo de Ahmut que viven en Marruecos desean o no cuidar de él; la razón que lleva al Tribunal a esta postura es que considera que Ahmut atendió estas necesidades del menor enviándolo a un internado en Marruecos. La conclusión final del Tribunal es que, en tales circunstancias, no puede considerarse que el Estado demandado no haya llevado a cabo un balance justo entre el derecho del demandante de un lado y su propio interés en controlar la inmigración de otro.

El caso Sen (2001) es ambiguo: en primer lugar, el Tribunal maneja un concepto dinámico de vida familiar que sugiere cambios para casos futuros; en segundo lugar, sin embargo, invoca un precedente (el mencionado caso Gül) y construye una ratio decidendi centrada en el hecho de que los padres de Sen - una menor de nueve años de edad- vivían ahora en Holanda con otros dos niños - hermanos menores de Sen- nacidos y educados en este país. Esto llevó al Tribunal a entender que a Sen debía concedérsele un permiso de residencia a los efectos de no obstaculizar el derecho a la reunificación familiar de la menor. En mi opinión, sin embargo -y teniendo en cuenta el papel que debería desempeñar el Tribunal de Derecho Humanos 
en la lucha por la protección de los menores- la sentencia resulta bastante desafortunada y un detenido análisis de la misma no nos deja la impresión de que el anterior argumento sea un argumento a fortiori a partir de un nuevo concepto dinámico de la vida familiar, sino más bien el núcleo de la ratio decidendi en este caso particular. En efecto, la lectura de la sentencia hace pensar que, de no haber sido porque los dos hermanos menores de Sen habían nacido y se habían educado en Holanda, la conclusión del razonamiento del Tribunal hubiera sido otra -sin permitir, por lo tanto, entender que éste vaya a operar para casos futuros a partir de un concepto dinámico de vida familiar-.

El caso Moustaquim vs. Bélgica (1991) se ocupa también de una cuestión de reunificación familiar pero los hechos concernidos son bastante diferentes a los de los supuestos anteriores. Moustaquim llegó a la edad de un año a Bélgica con sus padres. Tenía entonces un permiso de residencia. Durante su adolescencia se convirtió en un delincuente juvenil y fue condenado en diversas ocasiones. Cuando alcanzó la edad de veintiún años fue deportado de Bélgica. La decisión del Tribunal consistió en entender que había habido una violación del artículo 8 de la Convención pero no del artículo 14. Sin embargo, creo que la respuesta que dio el Tribunal a la demanda presentada por Moustaquim en la que alegaba haber sido víctima de una discriminación por razón de su nacionalidad -discriminación contraria al artículo 14 junto con el artículo 8- en relación con los delincuentes juveniles de dos categorías (aquellos con nacionalidad belga y aquellos con nacionalidad europea, que no podían ser deportados) comporta una petición de principio. En efecto, el TEDH se limita a sostener que el artículo 14 protege a los individuos que encontrándose en la misma posición que terceros sean objeto de cualquier medida discriminatoria en relación con el disfrute de derechos y libertades reconocidos en la Convención. En opinión del Tribunal, en este caso el demandante no puede ser comparado con los delincuentes juveniles belgas: el derecho a permanecer en su propio país y a no ser expulsados del que disfrutan (según el protocolo 4 de la Convención) los nacionales (así como los nacionales de otros países europeos) no se extiende a los nonacionales que disfrutan de un permiso de residencia. Parece, sin embargo, que invocar, como hizo el demandante, el artículo 14 hubiera requerido una mayor argumentación por parte del Tribunal antes de desestimar la violación del mencionado artículo. Más adelante volveré sobre este punto.

En el caso Bensaid vs. Reino Unido (2001) es el interés en el cuidado de la propia salud mental de un nacional de Argelia el que está en juego. Los hechos del caso son los que siguen. En 1995, ya en el Reino Unido, Bensaid comenzó a sufrir los primeros síntomas de una enfermedad psíquica. Por aquel entonces los médicos comenzaron a suministrarle psicofármacos 
(olanzapine). En relación con su status en el territorio británico es preciso señalar que si bien Bensaid entró con un visado de estudiante, obtuvo después la nacionalidad por matrimonio. Nacionalidad que perdió más tarde cuando, debido a su posterior divorcio, las autoridades consideraron que las razones para su disfrute ya no le eran aplicables. Además, las sospechas por parte de la autoridades de que aquél no había sido más que un matrimonio de conveniencia les llevaron a no concederle a Bensaid ningún otro permiso para residir en el país. De esta forma, se le comunicó la intención del gobierno de expulsarlo del territorio británico.

En relación con este caso el examen del Tribunal consiste en valorar si a la vista de su estado de salud actual pudiera haber un verdadero riesgo de que las consecuencias de ser expulsado comportaran una violación del artículo 3 (prohibición de tratos inhumanos o degradantes). El examen médico muestra que el demandante corría el riesgo de sufrir una recaída aun en el caso de permanecer en el Reino Unido, ya que su enfermedad era crónica y requería atención constante. A partir de esto, el Tribunal argumenta que si bien pudiera entenderse que la expulsión podría aumentar el riesgo al ser probablemente menores tanto la atención personal como la posibilidad de acceder al tratamiento médico - que está también a disposición del demandante en Argelia-, el hecho de que las circunstancias del demandante en ese país vayan a ser menos favorables que las que disfruta en el Reino Unido no se presenta como un argumento decisivo a los efectos de considerar que en caso de expulsión vaya a haber una violación del artículo 8 (respeto por la vida privada de los individuos). De esta forma, el Tribunal estima las alegaciones del gobierno en relación con el caso en cuestión: la política inmigratoria estatal era necesaria para el bienestar económico del país, para la salvaguarda del orden público y para la lucha contra la actividad delictiva, y que el NHS pasara a ser responsable de proveer tratamiento a una clase potencialmente abierta de ciudadanos no-europeos tendría serios efectos desestabilizadores.

El caso Cisse vs. Francia (2002) nos permite ver también el resultado de la ponderación de intereses hecha por el Tribunal en un supuesto similar. Cisse era miembro de un grupo de extranjeros sin permiso de residencia que en 1996 decidieron embarcarse en una acción colectiva con el fin de llamar la atención sobre las dificultades de ver revisado su estatuto de inmigrante en Francia. Su campaña culminó con la ocupación de la Iglesia de San Bernard en París el 28 de Junio de 1996 por un grupo de aproximadamente doscientos inmigrantes "sin papeles", muchos de los cuales eran de origen africano. El grupo contaba con el apoyo del párroco y de su consejo parroquial (las ceremonias religiosas tuvieron lugar sin ningún incidente). Diez hombres del grupo decidieron ponerse en huelga de hambre. El 22 de Agos- 
to de 1996, el comisario de policía de París firmó una orden de evacuación total del recinto. Fue hecha sobre la base de que la ocupación del recinto no estaba relacionada con ninguna manifestación religiosa; que había habido un notable deterioro en las ya poco satisfactorias condiciones sanitarias del lugar, se habían colocado cerrojos en las salidas de la iglesia y había riesgos sanitarios, riesgos para la paz, la seguridad y el orden público. A la mañana siguiente la policía llevo a cabo la evacuación. Todos los ocupantes de la Iglesia fueron detenidos e interrogados. A los ocupantes blancos se les dejó marchar inmediatamente mientras que la policía reunía a todos los ocupantes de color, además de a todos aquellos que se habían declarado en huelga de hambre, para enviarlos en autobús a un centro de detención de extranjeros. Se emitieron órdenes de detención y deportación para la mayoría de aquellos implicados. Pues bien, en relación con este caso el Tribunal apunta que si bien no comparte el punto de vista del gobierno acerca de que la ilegalidad del inmigrante fuera razón suficiente para justificar la violación de su derecho de reunión, considera que -aunque la reunión en sí era pacífica y no implicaba por sí sola una alteración del orden público ni impedía la entrada de los feligreses a sus ceremonias religiosas- la situación, tras dos meses de ocupación continua de la iglesia por los inmigrantes ilegales, incluido aquí el demandante, había acabado por convertirse en una situación de deterioro de la salud de los declarados en huelga de hambre y en la que las condiciones sanitarias habían devenido completamente inadecuadas e insostenibles. A la vista de tales circunstancias, el Tribunal aceptó que las restricciones al ejercicio del derecho de reunión del demandante podrían haber devenido necesarias. El Tribunal lamenta los métodos empleados por la policía, pero hace ver sin embargo que -conforme a las leyes del Estado- ésta podía intervenir sin precisar para ello que el párroco lo solicitara y que, por otra parte, ni el temor de las autoridades por que la situación hubiera podido deteriorarse rápidamente ni su consideración de que no podía prolongarse fueron irrazonables. De ahí que el TEDH no considerara la intervención como algo desproporcionado.

11. Lo que sigue a continuación es un esquema tentativo de las reglas que pudieran reconstruirse a partir de estas sentencias del Tribunal Europeo de Derechos Humanos. Encabezando cada regla doy cuenta de los principios que han sido ponderados para cada caso en cuestión:

\section{Reunificación familiar vs. bienestar económico del país}

a) Cuando sea el caso que la mayoría de los miembros de la familia (progenitores y hermanos) sean inmigrantes que disfruten ya de permiso de residencia: puede haber buenas razones para dar prioridad a la concesión de otro permiso de residencia a los efectos de reunificación sobre considera- 
ciones relativas al bienestar económico del país (en este sentido puede verse los casos Moustaquim y Sen antes presentados).

b) Cuando sea el caso de que sólo uno de los progenitores sea residente o naturalizado en el país, aun tratándose el solicitante del permiso de residencia de un menor, puede darse prioridad al bienestar del país. En tales casos al menor se le deniega el permiso y el progenitor es invitado a marcharse del país y regresar al suyo de origen para de esta forma poder disfrutar de la vida familiar que desea tener (en este sentido, puede verse el caso Ahmut).

Riesgos para la salud vs. bienestar económico del país

a) En el caso de que no quede probado que la salud del inmigrante indocumentado (aun si, inicialmente, residente) bajo tratamiento vaya a verse fuertemente afectada con la deportación, el bienestar económico del país debe ser privilegiado.

Interferencia en la vida privada vs. seguridad, prevención del desorden y de los delitos

a) En los casos en los que un inmigrante con permiso de residencia haya cometido un delito, podrá ser deportado tras el cumplimiento de su condena de prisión cuando tal sea una medida razonable para luchar contra el desorden y la actividad delictiva.

El Tribunal, sin mayor argumentación, considera que los nacionales y los extranjeros con permiso no pueden ser considerados en igualdad de condiciones a estos efectos; conforme con el TEDH, el diferente trato en la esfera del Derecho penal no es considerado como una violación del artículo 14 (igualdad de trato) de la Convención (éste era el sentido del caso Moustaquim).

\section{Libertad de reunión de los extranjeros indocumentados para denunciar} el trato recibido bajo ciertas leyes de inmigración vs. seguridad y riesgos contra el orden público

a) La libertad de reunión de los inmigrantes indocumentados debe ser "tolerada" durante un tiempo (dos meses es considerado por el Tribunal como un período razonable). Más allá de tal plazo, la seguridad y el orden público deben prevalecer. La deportación es, en tales casos, legítima.

12. Algunas consideraciones más:

a) El derecho a la reunificación familiar no se aplica de la misma forma a los nacionales de origen que a los nacionales por naturalización (caso Ahmut). Por lo que se refiere a los derechos que deben ser implementados y protegidos, en nuestras sociedades parecen existir "por ley" metecos (sobre esta idea volveré más adelante). 
b) Moustaquim, el demandante en el caso Moustaquim vs. Belgium, apuntó a un elemento moralmente sospechoso de muchos sistemas penales. No entro aquí a analizar aquellos casos en los que un inmigrante no documentado comete un crimen y, cumplida la pena de prisión, es deportado para perseguir de este modo el restablecimiento de un determinado status quo. Aunque en tales casos la deportación parece una medida administrativa sospechosa, no me lleva al tipo de consideraciones que aquí quiero introducir y que son relevantes cuando confrontamos la doble sanción sufrida por los sujetos cuyo estatus es el de extranjero con permiso de residencia. Como mencioné anteriormente, la dicotomía extranjero/nacional bien establecida en nuestros sistemas jurídicos lleva al TEDH a incurrir en una suerte de falacia de petición de principio en el caso Moustaquim. La discriminación prohibida por el artículo 15 de la Convención- afirma el Tribunal-, es la que tiene como víctima a un sujeto que se encuentra en la misma situación que un tercero. En este punto -y en relación con el caso de Moustaquim-, el Tribunal estima suficiente argumentar que un extranjero residente no es igual a un nacional o a un ciudadano europeo por lo que toca a las consecuencias legales derivadas de la comisión de un delito. Pero ¿no es precisamente ésa la cuestión que debería ser objeto de reflexión? Es decir: si es o no moralmente legítimo establecer un sistema penal que castigue con mayor gravedad a parte de la población residente (aquella con permiso de residencia) en la comunidad política en cuestión cuando el delito cometido tiene la misma gravedad. La clase de los metecos reaparece de nuevo desafiando así los fundamentos que pretenden ser moralmente correctos de sociedades como la europea.

c) El caso Bensaid también arroja luz en las prácticas jurídicas en relación con la inmigración. No cabe duda de que es razonable pensar que suministrar tratamiento médico público a una clase potencialmente abierta de no-ciudadanos podría tener efectos desestabilizadores para el Sistema Nacional de Salud de un determinado país. Pero, en mi opinión, el caso en cuestión podría haber permitido al Tribunal estimar (como quedó reflejado de hecho en uno de los votos particulares) que, a la luz de las específicas circunstancias del caso (el demandante había recibido ya ayuda médica durante su período como residente), se producía una violación del artículo 3 de la Convención (prohibición de trato degradante). Por otra parte, ya desde un punto de vista mínimamente autocrítico, es claro que estamos compelidos a preguntarnos qué tipo de relación mantenemos y a qué tipo de compromisos estamos obligados con aquellos individuos que en algún momento han sido aceptados en nuestra comunidad. Más adelante exploraremos las opiniones de Walzer sobre este punto. 
d) Las circunstancias en el caso Cisse rayan la vulnerabilidad absoluta. ¿No requiere el derecho de reunión -especialmente cuando los agentes pertenecen a un grupo particularmente vulnerable (individuos que protestan en contra de la política inmigratoria y que se enfrentan a deportación inmediata)- deberes más intensos por parte del Estado?

Tal y como yo veo las cosas, las lecciones extraídas de la jurisprudencia del Tribunal Europeo de Derechos Humanos dejan poco lugar para el optimismo. De momento, el estatus de ciudadano parece ser -como apunta Carens $^{14}$ - una especie de barrera feudal a la movilidad (finalmente esto es lo que sucede con aquellos que se encuentran en el nivel más alto de vulnerabilidad, como ilustra el caso Cisse), el estatus que nos protege contra la doble pena (como en el caso Moustaquim) y el criterio indispensable para que sea tomada en serio cualquier alegación de un interés en la reunificación familiar (particularmente aparece ilustrado esto por el caso Ahmut).

Puede que muchos piensen en este momento que las cosas son considerablemente más complejas de lo que reflejan las críticas precedentes. No tengo ninguna duda de que posiblemente tengan razón. Pero tal vez estas sentencias del TEDH que he reseñado $-y$ pese a la acaso excesiva simplicidad con que he presentado los conflictos de intereses implicados- deban hacernos sentir lo suficientemente incómodos desde un punto de vista estrictamente moral como para impulsarnos a arrojar algunas severas dudas razonables sobre la justificación de la dicotomía extranjero/ciudadano. No otra era mi pretensión en este apartado.

\section{Inmigración, fronteras y políticas de asilo en la Unión Europea}

13. Las líneas principales de lo que pretende ser la política de convergencia europea en materia de inmigración pueden ser extraídas de las conclusiones de la presidencia de los Consejos de Tampere (1999), Laecken (2001), Tesalónica (2003) y Bruselas (2003). Comenzaré exponiendo un párrafo de uno de esos documentos (el de Tampere) en cuanto que es muy ilustrativo de las tensiones que están en juego:

"Desde sus inicios mismos, la integración europea ha estado firmemente enraizada en un compromiso compartido de libertad, sustentando en los derechos humanos, en instituciones democráticas y en el Estado de Derecho. [...] Corresponde ahora al Tratado de Ámsterdam recoger el desafio de garantizar que esa libertad, en la que se incluye el derecho a circular libremente por toda la Unión, pueda disfrutarse en condiciones de seguridad y justicia accesibles a todos. Sería, además, contrario a las tradiciones europeas negar esta libertad a aquellas personas a las que sus circunstancias conducen justificadamente a tratar de acceder a nuestro territorio. Por esta razón, la Unión ha de desarrollar políticas

\footnotetext{
${ }^{14}$ CARENS 1987.
} 
comunes en materia de asilo e inmigración teniendo en cuenta al mismo tiempo la necesidad de llevar a cabo un control coherente de las fronteras exteriores para poner fin a la inmigración ilegal y para luchar contra quienes la organizan y cometen delitos internacionales conexos. [...]También debe desarrollarse un planteamiento común que garantice la integración en nuestras sociedades a los nacionales de terceros países que residen legalmente en la Unión" ${ }^{15}$.

Los hilos centrales de estos documentos conducen a una clara distinción, a los efectos del trato que recibirán en el territorio europeo, entre la conocida como inmigración indocumentada y la inmigración documentada:

A) La Unión Europea debe asegurar un trato justo a los nacionales de terceros países que residan legalmente en el territorio de los Estados miembros. Una política de integración más fuerte debería tratar de garantizarles derechos y obligaciones homologables a los de los ciudadanos europeos. El Consejo de Europa asume el compromiso de que a los nacionales de terceros países que posean residencia legal permanente se les debe dar la oportunidad de obtener la nacionalidad de los Estados miembros en los que son residentes (Tampere 1999).

Debe aumentarse la no discriminación en la vida económica, social y cultural y deben desarrollarse más medidas en contra del racismo y de la xenofobia. Considerando que una integración exitosa contribuye a la cohesión social y al bienestar económico, tal política debe cubrir cuestiones tales como el empleo, la participación económica, la educación y las habilidades lingüísticas necesarias, la salud y servicios sociales, la vivienda y asuntos relacionados con la vida urbana, así como la cultura y la participación en la vida social. En este sentido, el Consejo europeo da la bienvenida al hecho de que se ha llegado a un acuerdo acerca de las directivas en materia de reunificación familiar y residencia permanente, instrumentos ambos esenciales para la integración de nacionales de terceros países (Tesalónica 2003). Las fronteras serán abiertas cuando el desarrollo económico y demográfico lo permita y en tales circunstancias tendrán prioridad quienes procedan de países que compartan lazos históricos y culturales con el país anfitrión (Tesalónica 2003).

En Bruselas (2003) se reconoce que cada Estado miembro es responsable del número de inmigrantes legales admitidos en su territorio.

B) Por lo que se refiere a los inmigrantes indocumentados, la tendencia es por el contrario a endurecer las medidas. La gestión principalmente administrativa de las fronteras, el control de los visados y la repatriación de los inmigrante "ilegales" son los principales rasgos de la política inmigratoria de convergencia.

\footnotetext{
${ }^{15}$ Consejo europeo de Tampere, 15 y 16 de Octubre de 1999. Parágrafos 1 a 4.
} 


\section{Conversaciones en la frontera sobre legitimidad}

14. Algo muy asumido en relación con la pertenencia a una determinada comunidad política es que quienes han nacido en un determinado territorio o de padres que eran nacionales de una determinada comunidad política poseen más títulos para acceder a los beneficios de la nacionalidad que quienes son considerados demandantes "fortuitos". En el trabajo de Carens "Aliens and citizens" 16 encontramos algunos de los argumentos más recurrentes en contra de la apertura de fronteras ${ }^{17}$ :

a) La inmigración reduciría el bienestar económico de los ya ciudadanos.

b) Los flujos inmigratorios destruirían la cultura e historia de la sociedad de acogida. El carácter del país y su cohesión interna podrían verse afectados por la admisión de solicitantes "ocasionales o fortuitos".

c) Los flujos inmigratorios pueden afectar el orden y la integridad de los procesos políticos internos.

15. En los párrafos que siguen haré una breve presentación de los análisis de Walzer, Singer, Habermas y Ackerman en relación con el debate acerca de la apertura de fronteras. Como veremos, estos análisis constituyen un desafío -mayor o menor según los casos-a diversos aspectos de las políticas actuales en relación con la inmigración. Examinaremos entonces cuáles de los mencionados argumentos convencionales en contra de la apertura de fronteras son aceptables desde el punto de vista de cada uno de los referidos análisis y cuáles no superarían el test de legitimidad moral.

15.1 Aun cuando el trabajo de Walzer (Spheres of Justice) ${ }^{18}$ ha sido la fuente de referencia de argumentos en favor de la legitimidad del cierre de fronteras, hay una parte de su análisis que, en mi opinión, no ha sido suficientemente atendida. Me refiero a sus críticas contra las actuales políticas en materia de trabajadores invitados [guest workers], es decir, en materia de inmigrantes por razones económicas con permiso de residencia temporal en las diversas comunidades políticas occidentales. Me referiré a este aspecto de su teoría unas páginas más adelante.

En la teoría de Walzer, el cierre de fronteras es -asumiendo algunas restricciones- legítimo. Las políticas de admisión, nos dice, están parcialmente diseñadas atendiendo a consideraciones económicas y políticas del país anfitrión, a consideraciones acerca del carácter y "destino" de este mismo país y, por último, a consideraciones acerca del carácter de los países (como comunidades políticas) en general. Estos últimos son los argumentos

\footnotetext{
${ }^{16}$ Carens 1987: 251-273.

${ }^{17}$ En este sentido puede verse también SidGWICK 1891.

${ }^{18}$ WALZER 1983: 431-63.
} 
más importantes, puesto que nuestra comprensión de los países en general determinará si un determinado país u otro tienen el derecho que convencionalmente reclaman a distribuir la pertenencia o membrecía a ellos según los criterios y a partir de las razones que cada país considere en su caso particular como relevantes. El argumento de Walzer consiste en entender que dado que la diferencia de culturas y grupos es un valor, tal y como lo perciben muchas personas, y dado que no es posible proteger la diferencia sin algún tipo de cierre, entonces tal cierre debe permitirse en algún grado. Walzer elabora su argumento a través de una serie de gruesas comparaciones: las vecindades, clubes y familias. El problema en cuestión es: ¿cómo deben ser los países? Podría argumentarse en favor de la existencia de unos requisitos de admisión apelando a la condición y carácter del país de acogida y a la comprensión compartida de la comunidad en cuestión por parte de los que ya son miembros de ella. Como sucede en los clubes -sostendría este argumento- los sujetos solicitantes pueden dar buenas razones por las cuales consideran que deben ser elegidos como miembros, pero ninguno de ellos tiene derecho a ser miembro del grupo en cuestión.

Al margen de que este argumento pueda ser juzgado moral y políticamente, lo cierto es que, como cuestión de hecho, los ya ciudadanos de una determinada comunidad política se sienten moralmente obligados a abrir las fronteras de su país, seguramente no a cualquiera que quiera pertenecer al grupo, pero sí a cierto tipo de no miembros que son reconocidos como "familiares" nacionales o étnicos. En este sentido -apunta Walzer-, los Estados se asemejan a las familias más que a los clubes, puesto que es un rasgo de las familias que sus miembros estén moralmente unidos a personas que ellos mismos no han elegido y que viven fuera del hogar familiar. Los Estados reconocen lo que denominamos "principio de parentesco" cuando dan prioridad en el proceso inmigratorio a los familiares de sus nacionales. Es una forma de reconocer que la movilidad laboral -como Walzer argumenta- tiene un coste social: dado que los trabajadores son hombres y mujeres con familias, no se puede admitir a los primeros por el trabajo que realizan sin asumir algún tipo de compromiso en relación con sus padres ancianos, o hermanos y hermanas enfermas. En este sentido, la línea principal argumentativa de Walzer fluye de la siguiente forma: la justicia política impide mantener de forma permanente a ciertos individuos como extranjeros. Según esto, los ciudadanos de un Estado democrático tienen que hacer una elección: si quieren traer a nuevos trabajadores, deben estar dispuestos a relajar sus criterios de pertenencia; si no están dispuestos a aceptar nuevos miembros, entonces deben ingeniárselas para encontrar dentro de los límites de su propia fuerza de trabajo la forma de conseguir que el trabajo socialmente necesario sea llevado a cabo. Ningún Estado que pretenda ser 
democrático puede tolerar el establecimiento de un status fijo entre el de ciudadano y el de extranjero (aunque, sin duda, es posible admitir períodos de transición desde la pertenencia a una comunidad política a la pertenencia a otra). Los hombres y la mujeres o bien están sometidos a la autoridad de un Estado o no lo están; y si lo están entonces se les debe dar voz y voto, en definitiva igual voz y voto que tienen el resto de personas que residen en ese territorio, en relación con lo que hace la autoridad. Cuando eso no sucede así -concluye Walzer-, la comunidad se transforma en una tiranía ${ }^{19}$.

Por sí solo, lo que Walzer reclama -seguramente el lector estará de acuerdo-implica una crítica de las prácticas actuales de los diferentes Estados europeos: el trato igualitario en relación con aquellos que han sido inicialmente admitidos entre nosotros a los meros efectos de constituir fuerza laboral no es, ciertamente, una realidad constatable (baste aquí remitirse a los casos ya vistos presentados ante el TEDH).

Sin embargo, en mi opinión, hay todavía espacio para críticas adicionales. El argumento de Walzer sigue resultando condescendiente con una política inmigratoria particularmente restrictiva. Como algunos liberales (Singer, Habermas) han argüido, la teoría de Walzer legitima de algún modo las políticas actuales que son claramente restrictivas en relación con la entrada de inmigrantes. En mi opinión, estos autores tienen razón. Walzer no ataca el segundo argumento convencional en contra de la inmigración (los flujos migratorios destruirían la cultura y la historia de la sociedad en cuestión; el carácter de una comunidad y su cohesión interna pueden verse afectados por miembros "fortuitos" o "casuales"). Lejos de hacerlo, sostiene que la preservación de la identidad de una cultura e historia en particular justifica la exclusión de la comunidad de -especialmente- un cierto tipo de extranjeros. Como he apuntado, otros autores han desafiado este tipo de obstáculos y han sido expresamente más críticos también en relación con otro de los argumentos: el que apela al "bienestar económico del país".

15.2 En "Los de dentro y los de fuera" (Ética práctica) ${ }^{20}$, y tras denunciar la opulencia de las sociedades occidentales, Singer sostiene que las políticas inmigratorias deberían tener presentes los intereses de todos los afectados. Allí donde se enfrentan los diferentes grupos, tenemos que considerar en igualdad de condiciones los diversos intereses en juego. Esto significa -sostiene Singer- que intereses más apremiantes y fundamentales deben tener prioridad sobre intereses menos fundamentales. En relación con el problema del que aquí nos ocupamos, los intereses que están en juego son: 1) Por un lado, los de los refugiados. A veces, los intereses de los refugiados en ser

\footnotetext{
${ }^{19}$ WALZER 1983: 60-61.

${ }^{20}$ Singer 1995: 308-328.
} 
aceptados son muy básicos: tales son los casos en los que lo que está en juego es la propia vida. En otros casos, puede ser que la situación no sea de vida o muerte, pero que pueda afectar de manera importante el curso global de la vida de una persona (éste es el caso de lo que he venido denominando refugiados por razones económicas, y en los que me centro, por las razones antes expuestas, en este trabajo); 2) Por otro lado, los intereses del grupo de los residentes del país de acogida. Cuánto van a verse afectados -prosigue el argumento de Singer- va a depender del número de refugiados admitidos, de cómo se integren en la comunidad y del estado actual de la economía nacional en cuestión, entre otras variables. De hecho, algunos residentes pueden verse más afectados que otros: algunos pueden verse en la necesidad de competir en la búsqueda de trabajo con los inmigrantes, mientras que otros no enfrentarán esta situación, algunos se encontrarán viviendo en una vecindad con un alto número de inmigrantes, mientras que otros no. Sin embargo - puntualiza Singer- no debemos asumir que los residentes del país de acogida vayan a verse afectados - como balance global- necesariamente de forma negativa: al contrario, puede suceder que la economía se vea revitalizada de admitirse un número alto de inmigrantes y que ante muchos residentes pueda presentarse la ocasión de montar negocios para suministrar los bienes que necesiten para cubrir las necesidades de esos nuevos habitantes, que otros puede que disfruten con la atmósfera más cosmopolita del país, etc. También pueden darse otras posibles y más difusas consecuencias -subraya Singer- acerca de las cuales debemos pensar: una política inmigratoria menos restrictiva puede comportar en el futuro un mayor flujo de inmigrantes; la población "excedente" puede acarrear un aumento adicional en los servicios sociales (aprendizaje del idioma de la comunidad en cuestión, viviendas en los primeros meses, colocación y entrenamiento laboral). Pudiéramos también preguntarnos si el aumento de habitantes procedentes de otras comunidades pudiera suponer un rebrote de sentimientos racistas. Pero, por otra parte, la no aceptación de las solicitudes de admisión podría tener también efectos negativos: la estabilidad económica y la paz mundial dependen de la cooperación internacional basada en determinadas medidas que presupongan respeto y confianza.

¿Cuál es en opinión de Singer la ponderación adecuada de los intereses en juego? Singer construye un argumento hipotético: como los intereses de los refugiados por reinstalarse en un país más próspero siempre serán mayores que los intereses en conflicto de los residentes de tales países, ¿implicará esto que el principio de igual consideración de los intereses en juego nos lleva necesariamente a un mundo en el que todos los países deben continuar aceptando inmigrantes hasta que estén en una situación de pobreza y sobrepoblación similar a aquellos países del mundo de los cuales los individuos 
están emigrando? El argumento en favor de la inmigración no puede llevarnos tan lejos, apunta Singer: puede llegar un punto en el que, por ejemplo, la comunidad de acogida haya eliminado cualquier lujo que pusiera en peligro el medio ambiente y que aun así la satisfacción de las necesidades básicas crecientes de la población en aumento estuviera poniendo bajo mucha presión un sistema ecológico frágil de forma que una expansión causaría daños irreparables. O pudiera llegar un momento en el que la tolerancia en una sociedad multicultural se rompiera debido al resentimiento por parte de los miembros residentes originarios al considerar que sus hijos no pueden acceder a puestos de trabajo ante la competencia de nuevos inmigrantes muy eficientes; tal ruptura de la tolerancia puede alcanzar un punto en el que se pusiera en peligro grave la paz y la seguridad de todos los inmigrantes previamente aceptados y de los inmigrantes de otras culturas. Sólo entonces, la ponderación de intereses arrojará el resultado inverso. De todas maneras -concluye Singer - la actual aceptación de inmigrantes es susceptible de ser considerablemente aumentada antes de tener que sufrir alguna de las consecuencias recién apuntadas. La teoría de Singer -a diferencia de la de Walzer- no pretende mantener el argumento de la preservación de la cultura, historia y carácter de un determinado país como un argumento importante contra la apertura de fronteras. Por lo demás, el bienestar económico de los ya ciudadanos (hasta un cierto límite legítimo sin que esto implique, en la teoría de Singer, una aceptación acrítica del status quo) así como el orden y la integridad del proceso político interno siguen siendo para este autor intereses que pueden legitimar políticas inmigratorias restrictivas llegado un determinado momento.

15.3 Habermas, como Singer, denuncia en su artículo "Ciudadanía e Identidad Nacional" 21 , la opulencia de las sociedades occidentales y subraya que la habilidad política para integrar inmigrantes depende de cómo perciba la población local las consecuencias sociales y económicas del fenómeno. En su opinión, el punto de vista moral nos impide contemplar este problema sólo desde la perspectiva de los habitantes de sociedades prósperas y pacíficas; debemos igualmente tener en cuenta la perspectiva de quienes inmigran a continentes extranjeros en busca de refugio o, en otras palabras, en busca de una vida que valga la pena vivir. Por otra parte, la pregunta acerca de si hay un derecho [legal right] a inmigrar es particularmente relevante en la situación en la que actualmente nos encontramos, cuando el número de aquellos que desean inmigrar excede de manera considerable el número de aquellos que se está dispuesto a aceptar en los países de destino. Una obligación de ayuda deriva especialmente de: (a) las crecientes interdepen-

\footnotetext{
${ }^{21}$ Habermas 1990: 619-644.
} 
dencias en una sociedad global que ha devenido cada vez más articulada a través del mercado del mundo capitalista y de los medios electrónicos de comunicación de masas; (b) el hecho histórico de que Europa sacó provecho de los flujos migratorios en el pasado y de una historia de colonización; y (c) el desenraizamiento de culturas regionales debido a la invasión de la modernización capitalista.

Habermas sostiene que el caso de los refugiados por razones económicas es el que ofrece un mayor desafío a las políticas que descansan en los denominados deberes especiales. Una respuesta aceptable en relación con este problema -afirma- requiere un análisis de las razones que subyacen a las obligaciones especiales, desde la perspectiva liberal. La línea fundamental de su argumentación sigue el análisis de Henry Shue en "Mediating duties" 22 . Si los deberes especiales derivan de la coordinación de la división moral del trabajo (tal y como Shue sostiene) y no de esferas cerradas de responsabilidad moral (tal y como algunos comunitaristas han defendido), entonces tenemos razones para aceptar que nuestra responsabilidad moral se extiende más allá de las fronteras de las comunidades políticas. Y se extiende especialmente -añadiría yo por lo que hace a los propósitos de este trabajo- en relación con aquellos sujetos que son víctimas del fracaso de algunas instituciones (entre ellas, algunos Estados) socialmente diseñadas para la implementación y protección de los derechos humanos.

En principio, la posición de Habermas a favor de la apertura de fronteras es decididamente fuerte. En efecto, Habermas sostiene que si nos tomamos en serio la demanda de quien desea inmigrar para disfrutar de una existencia libre y digna (y aquí está pensando en los refugiados por razones económicas a los que se refería Singer), entonces hemos de considerar que tal persona tiene argumentos fuertes (a partir de la posición originaria de Rawls) para reclamar su derecho a inmigrar. Las restricciones a tal derecho sólo pueden ser consideradas legítimas cuando son debidas a un conflicto con intereses de importancia similar tales como evitar graves conflictos sociales y cargas de tal magnitud que acabarían por poner en riesgo el orden público y el desarrollo económico del país. Frente a la teoría de Walzer, según Habermas ni unos antepasados comunes ni un idioma o educación común puede dar fundamento a privilegios en relación con la adquisición de la ciudadanía. Para que el derecho de una comunidad a preservar la integridad del modo de vida de sus ciudadanos sea considerado aceptable debe entenderse en un sentido no particularista: sólo universalizando el argumento c) apuntado al comienzo de este epígrafe -los flujos de inmigración pueden afectar el or-

\footnotetext{
${ }^{22}$ ShUE 1988: 600-608.
} 
den y la integridad del proceso político interno- podríamos considerarlo, en determinadas circunstancias, como razón para el cierre de fronteras.

Desarrollaré las objeciones habermasianas al segundo de los argumentos convencionales contrarios a la apertura de fronteras: recordemos que tal era el presunto riesgo de dejar a la comunidad de acogida desprovista de identidad si una política inmigratoria menos restrictiva fuera puesta en práctica. Habermas extrae algunos argumentos a partir de las paradojas que enfrenta la tesis comunitarista una vez aceptado que en muchos casos vivimos en comunidades que aceptan principios constitucionales de vocación universalista. Cuando la cultura de una determinada comunidad política está vinculada con principios constitucionales universalistas, lo más que se puede requerir a los inmigrantes es que acepten la cultura política de su nuevo hogar, sin que por ello tengan que abandonar su originario modo de vida. La integración política excluye culturas fundamentalistas; pero no justifica la asimilación coercitiva en favor de la reafirmación del modo de vida de la cultura prevaleciente en el país receptor ${ }^{23}$. O dicho en las palabras de Carens: "Las personas viven en comunidades con lazos y vínculos pero éstos pueden ser de diversa naturaleza. En una sociedad liberal, tales lazos y vínculos deben ser compatibles con los principios liberales. Una inmigración no restrictiva cambiaría el carácter de una comunidad, pero no dejaría a la comunidad sin carácter alguno" ${ }^{24}$.

El derecho moral a inmigrar que pudiera fundamentarse en la combinación de las razones antes mencionadas no justifica sin embargo, en opinión de Habermas, garantizar un derecho [legal right] a inmigrar, pero nos compele a practicar una política liberal en materia inmigratoria que abra la sociedad de la que somos miembros a los inmigrantes y que gestione los flujos de inmigrantes de conformidad con las posibilidades reales. Como Singer, Habermas considera que el umbral que constituye el límite a la admisión de inmigrantes no ha sido todavía alcanzado en las sociedades europeas que, por cierto, están disminuyendo demográficamente y que siguen siendo dependientes, aunque sólo sea por razones económicas, de la inmigración. La justificación moral de una política inmigratoria liberal comporta también, de acuerdo con Habermas, la obligación de no limitar la cuota de inmigrantes en función de las necesidades económicas del país de acogida -en otras palabras, limitada a los "bienvenidos profesionales especializados"-, sino establecer tales cuotas a partir de criterios que se consideren aceptables desde el punto de vista de todas las partes afectadas ${ }^{25}$. Razones de peso que

\footnotetext{
${ }^{23}$ Habermas 1993: 147.

${ }^{24}$ Carens 1987: 271.

${ }^{25}$ Habermas 1993: 148-149.
} 
deben ser atendidas son -en opinión del autor- la preservación de la estabilidad social y económica de las diferentes comunidades (siempre y cuando su legitimidad no sea dudosa, añadiría yo).

15.4 Traeremos aquí, finalmente, por ser especialmente ilustrativo, el hipotético diálogo en la frontera recreado por Ackerman en Social Justice in the Liberal State ${ }^{26}$. Me permitirá además introducir en el siguiente apartado de este trabajo un análisis crítico de la dicotomía extranjero/nacional a la luz del principio de dignidad.

Ackerman invoca lo que denomina un diálogo neutro como único diálogo moralmente legítimo. Una estructura de poder sería ilegítima si puede únicamente ser justificada mediante una conversación en la que una persona (o grupo) tenga que afirmar que ella (o ellos) es la autoridad moral privilegiada. La neutralidad implica en términos de Ackerman que ninguna razón es una buena razón si requiere que quien detenta el poder afirme (a) que su concepción del bien es mejor que la de cualquier otro conciudadano o (b) que, al margen de su concepción del bien, él/ella es intrínsecamente superior a uno o varios de sus conciudadanos.

Veamos a continuación cómo aborda el tema de la inmigración. Ackerman sostiene que un Estado liberal no puede funcionar como si fuera un club privado, esto es, tachando a potenciales miembros que no son vistos con buenos ojos por los actuales miembros. El Estado liberal no es un club privado; es más bien un diálogo público mediante el cual cada persona obtiene reconocimiento social de su posición como un ser libre y racional. Bajo tales condiciones no puedo justificar mi poder de excluir a otro sin destruir mi propia demanda de la condición de miembro de un Estado liberal ideal. Ackerman somete a observación la arraigada idea de que tenemos derecho a excluir de una comunidad a terceros.

Ackerman construye un diálogo hipotético en un ficticio mundo dividido en dos Estados-nación: el pobre Este y el próspero Oeste. Nos hace asumir hipotéticamente que las instituciones del Oeste están organizadas de una forma liberal, mientras que el Este es una dictadura autoritaria donde una pequeña élite declara su superioridad sobre las masas de población explotadas. Por último, el autor nos invita a asumir como parte de su respuesta a esta oscura realidad que el Oeste ha adoptado una política inmigratoria de próxima implantación que lleva a admitir un buen número de habitantes del Este, una cifra $Z$, en base a un criterio cronológico de solicitudes. De hecho, el número $\mathrm{Z}$ es tan alto que pone en dificultades la capacidad de las instituciones del Oeste para mantener un diálogo político liberal. La presencia de tantos extranjeros recién llegados genera tal ansiedad en la población nativa

\footnotetext{
${ }^{26}$ ACKERMAN 1980.
} 
que hará imposible detener la toma de poder por un grupo fascista con el fin de asegurar el control de los nativos sobre una subclase inmigrante. Aun así, los habitantes del Este siguen viniendo a la frontera en número considerable; la escena se desarrollaría de la siguiente manera en la frontera del Oeste protegida mediante armas:

"E: Solicito que se me reconozca como ciudadano de este Estado liberal.

W: Rechazamos su solicitud.

E: ¿Qué les da derecho a rechazarla? ¿Creen ustedes que fracasaría en mi intento por ser un ciudadano en un Estado liberal ideal?

W: No, para nada.

E: ¿Piensan ustedes que son mejores simplemente porque nacieron al oeste de esta frontera?

W: No. Si sólo se tratara de eso no dudaría en admitirle a usted.

E: Bueno, entonces, ¿cuál es el problema?

W: El hecho es que en el Oeste todavía estamos lejos de haber conseguido una tecnología perfecta en materia de justicia social; si admitimos más de $\mathrm{Z}$ nuevos miembros, nuestras actuales instituciones no podrían funcionar de forma más que expresamente autoritaria.

E: Pero ¿por qué he de llevar yo la carga de tal imperfección en el diseño de sus instituciones?

W: Lo sentimos, estamos haciendo todo lo que podemos. Pero Z es el límite de inmigrantes que podemos admitir.

E: No, ustedes no están haciendo todo lo que está en sus manos. ¿Por qué no expulsan a uno de los miembros del Oeste por nacimiento y dejan sitio para mi? ¿Acaso creen que ellos son mejores que yo?

$\mathrm{W}$ : Z es el límite de nuestra capacidad de asimilación a partir de la asunción de que existe un cuadro de nativos familiarizados con el funcionamiento de las instituciones liberales. Si algunos nativos fueran expulsados, $\mathrm{Z}$ inmigrantes sería entonces un número excesivamente alto.

E: ¿Qué se supone pues que debo hacer? Moriré antes de conseguir llegar a los primeros puestos en la fila de inmigrantes que puedan acceder en la próxima ocasión.

W: Vuelva con su gente y construya su propio Estado liberal. Trataremos de ayudarle lo mejor que podamos"27.

Una dura conversación -resume Ackerman-. Seguramente el lector está de acuerdo. Del mismo modo que sucedía con la teoría de Habermas, en la teoría de Ackerman, la preservación de las instituciones liberales es un obstáculo legítimo en la política inmigratoria.

\footnotetext{
${ }_{27}$ ACKerman 1980: 93-94.
} 
No intentaré analizar aquí las complejidades del argumento en contra de la expulsión de miembros nativos; hacerlo nos llevaría lejos del lugar al que nos conduce un análisis realista de las condiciones para la justicia social y especialmente lejos de las posibilidades actuales de cambio de las políticas en materia de inmigración. Me limitaré a apuntar ciertas dudas acerca de la carga impuesta sobre el individuo que hace el número $Z+1$. Un examen de este punto nos conduce a ser conscientes de las tensiones entre las denominadas razones institucionales y las razones sustantivas que afloran en esta conversación en la frontera o, por decirlo con las bellas palabras de Ricoeur, la tensión entre la generalidad de la regla jurídica y la consideración de la dignidad del ser humano particular ${ }^{28}$. Sobre esto volveré en el próximo apartado.

Pero continuemos antes con la argumentación de Ackerman. Sería absurdo insistir en que las autoridades en materia de inmigración prueben que la admisión de un individuo E pueda llevar a un levantamiento antiliberal. Dado que las revoluciones autoritarias no pueden ser previstas con rigor, lo más que podemos pedir es que los gobiernos fijen una cifra $\mathrm{Z}$ de inmigrantes que pueden ser admitidos al tiempo que son conscientes del derecho que prima facie tienen los inmigrantes a solicitar ser admitidos como miembros de un Estado liberal. Los habitantes del Oeste -siguiendo con el ejemplo recreado por Ackerman- no tienen legitimidad para denegar este derecho a los procedentes del Este a partir de la fundamentación meramente consistente en el hecho de haber nacido ellos en el otro lado de la frontera; tampoco pueden evitar las demandas de diálogo simplemente invocando que compartir "su" riqueza constituiría para ellos un inconveniente. Pues la cuestión es, precisamente, por qué E no puede esgrimir la pretensión de disfrutar de un punto de inicio semejante a la posición disfrutada por W. Después de todo ¿acaso sus intereses no valen igual que los nuestros? ${ }^{29}$

Como he apuntado, de la misma manera que Habermas, Ackerman sostiene que la única razón que justificaría una restricción en las políticas en materia de inmigración sería la salvaguarda del proceso de conversación liberal en marcha. Las personas que viven en el lado próspero de la frontera estarían obligados -afirma Ackerman- a hacer serios sacrificios en las inversiones en beneficio propio si pretenden convencer a otros de que su liberalismo es algo más que pura simulación. Hay formas más o menos liberales de gestionar los espinosos dilemas de la política de extranjeros, pero dos terribles respuestas gravitan -de acuerdo con Ackerman- sobre toda sociedad liberal en la que el crecimiento demográfico ha superado el

\footnotetext{
${ }^{28}$ Ricoeur 1995: 220. Puede verse también en este sentido AtienZa 2001: 201.

${ }^{29}$ ACKERMAN 1980: 95.
} 
desarrollo al nivel de los recursos -y en la medida en que así haya sido-; tales respuestas son: libertad sin legitimidad o legitimidad sin libertad.

\section{El principio de dignidad y los requisitos igualitaristas}

16. Podríamos decir que la teoría de Ackerman nos lleva a un caso extremo ayudándonos a apreciar tensiones morales inevitables. Sin embargo, creo que concluir sólo con esto implicaría una excesiva condescendencia con el modo en el cual están funcionando nuestras actuales instituciones. Puede ser que no podamos escapar a ciertos dilemas morales, pero también puede ser que el encontrarnos en tales situaciones en las que tenemos que hacer una elección trágica (cualquiera de las opciones escogidas nos llevará a sacrificar un bien considerado especialmente valioso) sea consecuencia a su vez de acciones previas moralmente incorrectas ${ }^{30}$.

17. Hasta aquí me he ocupado de forma preferente y más específica de algunos argumentos que la comunidad (el grupo de individuos que actualmente constituye la comunidad política) podría esgrimir para legitimar algunas restricciones a la entrada de inmigrantes. Vayamos ahora al otro principio en juego: el principio de dignidad. El principio de dignidad es el motor del ideal igualitario. La formula "igual tratamiento de las personas" ha jugado - como Bobbio ha puesto de manifiesto ${ }^{31}$ - un papel revolucionario en la historia y (si bien en una controvertida interpretación marxista de la historia) es una de las fuerzas impulsoras del progreso histórico. Cada intento por poner fin a cualquier tipo de discriminación, cualquier paso para lograr la inclusión, puede ser -bajo este paradigma- considerado un indicio de progreso. Los juicios acerca de la relevancia de las diferencias humanas de hecho constituyen juicios de valor y deben estar respaldados por una teoría moral bien fundada. La historia de los hombres y las mujeres es una historia llena de diferencias consideradas relevantes cuya supuesta legitimidad moral fue posteriormente cuestionada. La que viene siendo la crítica a la distinción de género como intento por justificar la exclusión de las mujeres del ámbito político y en general de la vida pública a lo largo de la historia podría ayudarnos a proyectar una suerte de ejercicio de memoria que probablemente nos ayude a recobrar la debida perspectiva moral. Esto es, a ser conscientes de la dimensión moral que necesariamente tienen nuestras decisiones acerca de incluir o excluir a determinadas personas cuando esté en juego si son o no beneficiarios de determinadas prestaciones sociales $\mathrm{y}$, finalmente, si pueden o no participar en la vida política institucional.

\footnotetext{
${ }^{30}$ Puede verse en este sentido Gowans 1997.

${ }^{31}$ Bоввіо 1977: 68-70, 92.
} 
18. La dicotomía extranjero/ciudadano está basada en un rasgo inmutable -el rasgo de poseer una determinada nacionalidad- sobre el cual el individuo no puede ejercer normalmente control de ningún tipo. Por su parte, el principio de dignidad prescribe que los seres humanos sean tratados de acuerdo con sus decisiones, intenciones y expresiones de consentimiento. En la medida en que adoptemos tal principio y no primen razones para adoptar ningún otro, se pone de manifiesto la ilegitimidad de cualquier medida que a efectos de distribuir recursos discrimine entre seres humanos sobre la base de rasgos que no están sujetos a su control ${ }^{32}$.

19. Hay quien ha sostenido que en el caso de los refugiados por razones económicas, la calificación como extranjero o ciudadano está bajo el control del agente puesto que éste acepta libremente colocarse bajo el sistema jurídico de un país diferente obteniendo de esta forma el status de extranjero o nociudadano ${ }^{33}$. Trataré de derrotar este argumento a partir de un desarrollo del concepto de dignidad. Hablar de control implica hablar de actos voluntarios. Podemos decir que un acto es voluntario en dos formas diferentes: a) cuando es el resultado de la voluntad del individuo y no concurren ni compulsión física ni movimientos reflejos. La voluntad del individuo es entonces el resultado de su propio balance de razones; b) cuando en el proceso de formación de la voluntad no concurren ni coerción ni miedo. Bajo esta definición se dará el caso de que ciertas razones pesan de tal modo en el acto de ponderar (no podemos reprochar a alguien por actuar apoyándose en ellas: pensemos en el recurrido ejemplo de darle dinero al atracador cuando me está apuntando con la pistola) que podrían "determinar" el resultado de la ponderación. Esto es, determinan la voluntad y, en tal sentido, no podemos considerar sus actos como libres: la acción no estaba verdaderamente bajo el control del individuo. Lo que sostengo es que el principio de dignidad está relacionado con esta segunda interpretación de la idea de un acto voluntario. Así, aun si los inmigrantes inician voluntariamente (en el primer sentido) su viaje, no es cierto que lo hagan en el segundo sentido. Permítaseme sugerir la noción de "determinismo de las razones" (esto es, razones que no podemos no atender) para dar cuenta de tales situaciones. Tomar la dignidad en serio me parece que implica considerar voluntarios sólo aquellos actos de la persona que no están determinados por razones que no pueden razonablemente no ser atendidas. Es decir, hay ciertas razones que, desde un punto de vista normativo no pueden quedar fuera del balance de razones; ese especial tipo de razones nos compele a actuar de una determinada forma. En tal sentido el acto en cuestión no es libre.

\footnotetext{
32 Para esta interpretación del principio de dignidad puede verse NiNo 1991: 267-301 .

${ }^{33}$ Hierro 1995: 142.
} 
20. Aun cuando es posible argumentar contra la idea de que los refugiados económicos se sitúan voluntariamente bajo un determinado sistema jurídico extranjero y que, por lo tanto, su dignidad sí que resulta violada en el sentido antes indicado cuando les imputamos mediante la fuerza las consecuencias previstas por el sistema jurídico en cuestión, lo cierto es que este tipo de argumento yerra el punto de ataque. En efecto, la cuestión relevante no es si el agente por sí mismo se puso o no voluntariamente bajo un sistema jurídico extranjero sino si la dignidad humana y las exigencias de la igualdad son violados cuando se le deniega la entrada (a) al territorio y al mercado laboral, (b) al sistema de beneficios de la seguridad social, (c) a la comunidad política simplemente a partir de su status de extranjero. Dado que la dicotomía ciudadano/extranjero socialmente construida (social y jurídicamente) descansa en una característica que no está bajo el control del agente, creo que sólo puede considerarse legítima si fuera posible derivar su moralidad de algún tipo de justificación moralmente sostenible del fundamento de los Estados, una justificación que, de no darse, expondría a dicha dicotomía al riesgo de ser moralmente sospechosa.

21. Quizá podría argumentarse que el diseño institucional bajo esta dicotomía es legítimo teniendo en cuenta -al modo en que Shue propone en su trabajo citado "Mediating duties"- cuál es la mejor división del trabajo en relación con la implementación de nuestros deberes positivos hacia los demás seres humanos. Sólo dentro de esos parámetros las consecuencias prácticas de esa dicotomía podrían verse como legítimas.

En una sociedad de gentes bien ordenada (tal como fue trazada por Kant $^{34}$ y después por Rawls ${ }^{35}$ ) tal dicotomía jugaría el papel recién indicado: en tal mundo, las personas muy probablemente no desearían trasladarse a otros países como lo hacen hoy en día (de hecho, parece que las personas en general tienen una tendencia a permanecer en su lugar de nacimiento en caso de poder proyectar una vida digna en el mismo). Bajo tales posibles -aunque de momento no realizadas- circunstancias, cuando alguien llegara a la frontera ninguno de los argumentos que pudieran presentarse según el anterior análisis como legítimos para negar la entrada (recordemos: la preservación del sistema económico y del sistema social) serían de aplicación, puesto que el número de solicitantes sería muchísimo menos alto de lo que lo es actualmente. En la línea de frontera la dicotomía no podría considerarse legítima.

Pero volvamos al status quo de nuestro mundo. En mi opinión, la legitimidad de la limitación en el número de admisiones a un cierto número $\mathrm{Z}$

\footnotetext{
${ }^{34}$ Kant 1795: 26.

${ }^{35}$ RAWLS 1999.
} 
de manera que pueda preservarse el desarrollo económico de la sociedad en cuestión -siempre que hablemos de un sistema legítimo- y sus instituciones liberales sólo puede ser suscrita si dos condiciones adicionales le son añadidas:

a) Cuando el sistema social corre el riesgo de un posible levantamiento protagonizado por miembros racistas de la sociedad de acogida, es cierto, aunque resulte duro admitirlo, que las políticas inmigratorias deben tener en cuenta este tipo de peligros. Ahora bien, en la medida en que tal riesgo en contra del orden público no emerge causado por un efecto acumulativo no intencionado de acciones individuales justas ${ }^{36}$ sino a causa de ciudadanos amotinados con el fin de evitar que otros ejerciten sus libertades legítimas, creo que un Estado verdaderamente democrático debería tener muy presentes, con el fin de informar a sus ciudadanos, cuáles son de hecho -y lejos de prejuicios de tipo xenófobo- las consecuencias económicas de los flujos migratorios al tiempo que -precisamente mediante esta información-trate de luchar contra los prejuicios racistas y xenófobos.

b) La limitación legítima se halla, sin embargo, en tensión con la necesidad de atender las razones de la persona en la frontera. ¿Por qué -por ponerlo en las palabras de Ackerman-sobre la persona $Z+1$ debe pesar el coste del funcionamiento del sistema?

Me gustaría sugerir que si -tal y como parece- hemos sido compelidos a enfrentar este tipo de tensión entre razones institucionales, por un lado, y la dignidad del individuo y los requisitos del igualitarismo, por otro, debido a actos moralmente ilegítimos realizados en el pasado o en el presente por parte de las sociedades occidentales -seguramente una de las causas principales del actual flujo de inmigrantes por razones económicas son las injustas estructuras de mercado que han ido sucediéndose a lo largo de la historia-, tenemos entonces que ser extremadamente cautelosos con el diseño de nuestras políticas migratorias. De hecho, bajo tales circunstancias, una dicotomía de dudosa legitimidad moral se convierte en moralmente grotesca.

\section{Epílogo}

22. El cínico podría todavía alegar incomodado un "liberemos a las sociedades del principio de dignidad y de sus molestas implicaciones: borrémoslo de todas las Constituciones". Pero, aun así, continuaremos estando obligados a hacer un análisis crítico de nuestras prácticas si, como alguien ha dicho ya, razones sumamente realistas (esto es, razones "prudenciales") son aquí invocables: nuestras vidas -y nunca más el mero mantenimiento de nuestro actual bienestar- pueden también estar en juego.

\footnotetext{
${ }^{36}$ RAWLS 1999.
} 


\section{Bibliografía}

Ackerman, B. (1980), Social Justice in the Liberal State, New Haven: Yale University Press.

Atienza, M. (2001), "Los límites de la interpretación constitucional. De nuevo sobre los casos trágicos" [1998], en VÁzQUEZ, R. (ed.), Interpretación jurídica y decisión judicial, México: Fontamara, 187-213.

BAYÓN, J. C. (1986), "Los deberes positivos generales y la determinación de sus límites. Observaciones al artículo de Ernesto Garzón Valdés”, Doxa, 3: 35-54.

Baubock, R. (2000), "Multicultural citizenship: Towards an European policy", Siirtolaisuus-Migration, 4: 4-14.

BeITz, C. (1983), "Cosmopolitan Ideals and National Sentiment", The Journal of Philosophy, 80/10: 591-600.

BoвBIo, N. (1993), Igualdad y libertad, trad. por P. Aragón, Barcelona: Paidós.

Carens, J. H. (1987), "Aliens and Citizens: The case for Open Borders", Review of Politics, 49: 251-273.

Cottingham, J. (1986), "Partiality, Favouritism and Morality", The Philosophical Quarterly, 36/144: 357-373.

Ferrajoli, L. (1999), Derechos y garantías. La ley del más débil, trad. por P. Andrés y A. Greppi, Madrid: Trotta.

- (2001), Los fundamentos de los derechos fundamentales, trad. por P. Andrés y otros, Madrid: Trotta.

- (2001), "Las razones del pacifismo", Jueces para la democracia, 48: 3-14.

Garzón Valdés, E. (1986) "Los deberes positivos generales y su fundamentación”, Doxa, 3: 17-34.

- (1986), "Algunos comentarios críticos a las críticas de Juan Carlos Bayón y Francisco Laporta", Doxa, 3: 65-68.

— (1993), "Intervencionismo y paternalismo" [1990], Derecho, Ética y Política, Madrid: Centro de Estudios Constitucionales, 379-399.

Goodin, R. E. (1988), "What is so special about our Fellow Countrymen?", Ethics, 98: 663-686.

Gowans, Ch. W. (1987), “The debate on moral dilemmas", en Gowans, C. W. (ed.), Moral dilemmas, Oxford: Oxford University Press.

Habermas, J., (1990), "Ciudadanía e identidad nacional", en Facticidad y validez, 1998, trad. por M. Jiménez Redondo, Madrid: Trotta, 619-643.

- (1993), "Struggles for recognition in Constitutional States", European Journal of Philosophy, 1/2: 128-155.

- (1996), "The European Nation State: its Achievements and its limitations. On the Past and Future of Sovereignty and Citizenship", Ratio Juris, 9/2: 125-137.

Held, D., Mcgrew, A., Goldblatt, D., Perraton, J. (1999), Global Transformation: Politics, Economics and Culture, Cambridge: Polity Press.

Hierro, L. (1995), "Las huellas de la desigualdad en la Constitución", en Reyes Mate (ed.), Pensar la igualdad y la diferencia. Una reflexión filosófica, Madrid: Argentaria/Visor, 131-150.

Kant, I. (2001), Sobre la paz perpetua [1795], trad. por J. Abellán, Madrid: Tecnos. 
LuCAS, J, DE, Torres, F. (eds.) (2002), Inmigrantes ¿cómo los tenemos?: algunos desafios y (malas) respuestas, Madrid: Talasa.

Miller, D. (1988), “The Ethical Significance of Nationality”, Ethics, 98: 647-662.

NIELSEN, K. (1983): "Global justice and the imperatives of Capitalism", The Journal of Philosophy, 80/10: 608-610.

Nino, Carlos S. (1993), The Ethics of Human Rights, Oxford: Clarendon Press.

Rawls, J. (1999), The Law of Peoples, Cambridge: Harvard University Press.

Pogge, T. W. (1999), “A Global Resources Dividend”, en Crocker, D. A./Linden, T. (eds), Ethics of Consumption: The Good Life, Justice, and Global Stewardship, Lanham (Md.): Rowman \& Littlefield: 501-538.

Ricoeur, P. (1995), Le Juste, Paris: Éditions Esprit.

Ruzz Miguel, A. (1989), "Problemas de ámbito de la democracia", Doxa, 6: 97120.

Santos, B. de Sousa (1995), Toward a New Common Sense: Law, Science and Politics in the Paradigmatic Transition, New York: Routledge.

Sassen, S. (1998), Globalitation and its Discontents. Essays on the New Mobility of People and Money, New York: The New Press.

SEn, A. (1999), Development as Freedom, Oxford: Oxford University Press.

SEN, A. (2002), "How to judge globalism", in www.prospect.org

Sidgwick, H.(1891), Elements of Politics, London: Macmillan, 1919 (4 ed.), disponible en http://cepa.newschool.edu/het/profiles/sidgwick.htm

Singer, P. (1995), "Los de dentro y los de fuera", en Ética Práctica, segunda edición, trad. Rafael Herrera Bonet, Ed. Cambridge University Press.

Shue, H. (1983), "The Burdens of Justice", The Journal of Philosophy, 80/10: 600608.

— (1988), "Mediating duties", Ethics, 98: 687-704.

Twinning, W. (2000), Globalisation \& Legal Theory, London etc.: Butterworths.

van Gunsteren, H.R. (1988), “Admission to citizenship”, Ethics, 98: 731-741.

Walzer, M. (1983), Spheres of Justice. A defence of Pluralism and Equality, New York: Basic Books. 